Review Article

\title{
The microbiome and inborn errors of metabolism: Why we should look carefully at their interplay?
}

\author{
Karina Colonetti ${ }^{1,2}$, Luiz Fernando Roesch ${ }^{3}$ and Ida Vanessa Doederlein Schwartz ${ }^{1,2,4}$ \\ ${ }^{1}$ Programa de Pós-Graduação em Genética e Biologia Molecular, Universidade Federal do Rio Grande do \\ Sul, Porto Alegre, RS, Brazil. \\ ${ }^{2}$ Laboratory of Basic Research and Advanced Investigations in Neurosciences (BRAIN), Hospital de Clínicas \\ de Porto Alegre, Porto Alegre, RS, Brazil. \\ ${ }^{3}$ Interdisciplinary Research Center on Biotechnology-CIP-Biotec, Universidade Federal do Pampa, Bagé, \\ RS, Brazil. \\ ${ }^{4}$ Medical Genetics Service, Hospital de Clínicas de Porto Alegre, Porto Alegre, RS, Brazil.
}

\begin{abstract}
Research into the influence of the microbiome on the human body has been shedding new light on diseases long known to be multifactorial, such as obesity, mood disorders, autism, and inflammatory bowel disease. Although inborn errors of metabolism (IEMs) are monogenic diseases, genotype alone is not enough to explain the wide phenotypic variability observed in patients with these conditions. Genetics and diet exert a strong influence on the microbiome, and diet is used (alone or as an adjuvant) in the treatment of many IEMs. This review will describe how the effects of the microbiome on the host can interfere with IEM phenotypes through interactions with organs such as the liver and brain, two of the structures most commonly affected by IEMs. The relationships between treatment strategies for some IEMs and the microbiome will also be addressed. Studies on the microbiome and its influence in individuals with IEMs are still incipient, but are of the utmost importance to elucidating the phenotypic variety observed in these conditions.
\end{abstract}

Keywords: Inborn errors of metabolism, microbiome, microbiota, diet, treatment.

Received: July 28, 2017; Accepted: January 19, 2018.

\section{Introduction}

The human body host a large amount of non-human genetic material, the microbiome, defined as the set of microorganisms, their genes, and the surrounding environmental conditions (Marchesi and Ravel, 2015). The human gut microbiome is believed to play an important role in the development of basic physiological systems, such as the digestive, immune, and nervous systems, and constitutes a virtual metabolic organ of unquestionable importance (Lopez-Legarrea et al., 2014; Suez et al., 2014; Maukonen and Saarela, 2015). The gastrointestinal (GI) tract is a metabolically rich environment that harbors approximately three-quarters of the body's immune cells, contains vagal afferent endings which respond to immune cells and immune and bacterial products (cytokines, proteases, 5Hydroxytryptimaine and $\mathrm{CRH}$ for corticotropin-releasing hotmone, $\mathrm{CRH}$, histamine), and has receptors for compounds produced by neuroendocrine cells (Omran and

Send correspondence to Karina Colonetti. Universidade Federal do Rio Grande do Sul, Rua Ramiro Barcelos, 2350, 90035-903 Porto Alegre, RS, Brazil. E-mail: kcolonetti@gmail.com.
Aziz, 2014). Diet and genes related to the immune system and metabolism are among the key factors with potential to alter the bacterial community present in the gut. Thus, the associations of diet, metabolism, the central nervous system, and the immune system with the development and composition of the gut microbiome has become the object of intense interest among the scientific community (Mayer et al., 2014).

Inborn errors of metabolism (IEM) are rare monogenic genetic diseases characterized by absent or deficient activity of a given enzyme and which can sometimes be managed with dietary strategies. The phenotypic heterogeneity found in IEMs is manifested mainly by the age at onset of symptoms, presence (or absence) of neurological compromise, and response to the treatment. In untreated phenylketonuria (PKU) and in propionic and methylmalonic acidemia patients, for instance, the neurological and behavior impairment are highly variable. The development of liver disease is common to several IEMs, such as tyrosinemia type 1 and urea cycle disorders. Also, the response to the treatment is not the same among patients with the same genotype. 
Convergent efforts of professionals in different fields have enabled the discovery of new mechanisms and processes whereby the microbiome can exert local and systemic effects. In this non-systematic review of the literature, we will focus on how the gut microbiome could influence the context of treatable IEMs.

\section{The human gut microbiome}

Among the various microbial habitats found in the human body, the GI tract harbors the vast majority of microbial cells (Sender et al., 2016). The composition of the microbiota varies along the GI tract, both quantitatively and qualitatively, depending on the environmental conditions (pH, oxygen, etc.) (Donaldson et al., 2016). In the small bowel (particularly the duodenum), the composition is similar to that of the stomach, while the large bowel (especially the colon) contains the majority of the gut's microbial population, as it is the site of fermentation, due to the availability of nutrients obtained from digestion (Madigan and Martinko, 2006).

Prior to the development of next-generation sequencing (NGS) techniques, the gene profile of these microorganisms had never been determined accurately (Grenham et al., 2011). The ability to obtain a large number of gene sequences in a short period of time and at relatively low cost led to the acquisition of an immense volume of data to which biological significance could then be ascribed (Cho and Blaser, 2012). Advances in these techniques, coupled with the development of bioinformatics tools, have allowed analysis of the gut microbiome to an extent that would have been impossible with bacterial cultures alone (Hiergeist et al., 2015). Furthermore, the use of NGS and bioinformatics techniques, with the aid of databases and computational and statistical algorithms, has allowed complex studies for the detection, quantification, and functional analysis of the human microbiome and its physiological associations, thus expanding knowledge of microbial ecology beyond simple pathogen $v s$. host relationships.

Initiatives such as the Human Microbiome Project, created in the United States in 2008, have sought to characterize the microbial communities of various sites in the human body, with a focus on analyzing the role of these microorganisms in sickness and in health (Human Microbiome Project Consortium, 2012). In Europe, a similar effort known as MetaHIT, which took place from 2008 to 2012, sought to study the association of the gut microbiome with several states of health and illness, prioritizing obesity and inflammatory bowel disease (Metagenomics of the $\mathrm{Hu}$ man Intestinal Tract, MetaHIT.

The results of the aforementioned initiatives have led to a new appreciation for the human microbiome from taxonomic and functional points of view. The microbiota is both functionally relevant and uniquely personal, differing even between monozygotic twins, what suggests that childhood exposure to different environmental factors is a determi- nant of development of the adult microbiota (Turnbaugh and Gordon, 2009). Despite great interpersonal variation in the microbiota, the metabolic roles of its microorganisms are highly conserved: enriching the biosynthesis of cofactors and vitamins, in addition to a key role in central carbohydrate metabolism, aromatic amino acids (AA), and ATP synthesis in the lower GI tract (Segata et al., 2011; Human Microbiome Project Consortium, 2012). This has given rise to the notion of a "functional core" of microorganisms rather than a core set of microbial taxa, as the same essential roles can be played by different taxa (Lloyd-Price et al., 2016).

The gut microbiota is influenced by the environment and affected by diet, medications, age, geographic factors, surgical interventions, and host genetics, particularly genes related to the immune system and metabolism (Yatsunenko et al., 2012; Dabrowska and Witkiewicz, 2016; Goodrich et $a l$., 2016). The gut microbiome suffers drastic changes during the first three years of life (Yatsunenko et al., 2012). After that, diet is one of the main factors that shape the gut microbiota (De Filippo et al., 2010; David et al., 2014), and the microbiome continues to evolve all lifelong (Ottman et al., 2012; Odamaki et al., 2016). Once diet is strongly correlated with cultural habits and is affected by geographic factors, such as availability of nutrients and source of carbohydrates, fibers and fat, one can also consider that culture affects the patterns found in the microbiome (Yatsunenko et al., 2012). To study the microbiome is also to study ecology. From an ecological point of view, maintaining sufficient bacterial diversity and richness is important for gut microbiota functional redundancy, adaptability and to provide a certain tolerance against environmental challenges, resilience (Gill et al., 2006). Western diets, rich in calories and refined sugar, are associated with lower richness in microbial communities at individual level (alpha diversity) and higher variation among individuals (beta diversity) when compared with diets high in fiber and relatively low in calories (Martínez et al., 2015). Individuals who consume a Western type diet with high-energy and high-fat intake present changes in metabolic and immune biomarkers, such as a higher body mass index and higher levels of inflammatory markers than those who follow a high-fiber, low-calorie diet (Cani et al., 2009). Taken together, these facts have led to associations between microbial richness and health. Once microbial richness is strongly associated with diet patterns (De Filippo et al., 2010; Cotillard et al., 2013; Sonnenburg and Sonnenburg 2014), both the composition and energy content of one's diet are important modulators of the microbiota (Oriach et al., 2016). Diet is a crucial driver of the composition of the microbial community from childhood to old age (Kashtanova et al., 2016) and has the potential to alter the bacterial metabolite profile, thus influencing the host's metabolism both directly and indirectly. 
The major bacterial metabolites known to influence the host include short-chain fatty acids (SCFAs) and vitamins. SCFAs are organic monocarboxylic acids with six or fewer carbon atoms, generated by anaerobic fermentation of indigestible dietary fibers (such as cellulose, xylans, and inulin) in the gut. The main SCFAs produced as a result of these fermentation processes are butyrate, acetate, and propionate. SCFAs are absorbed by the host and are important energy sources, corresponding to $10 \%$ of the energy source in a Western diet. Portal and hepatic veins contain large amounts of SCFAs (Cummings et al., 1987). SCFAs also stimulate growth of bacteria in the genera Lactobacillus and Bifidobacterium, these playing a key role in colon physiology and metabolism (Roy et al., 2006) and influencing the immune and inflammatory responses (Maslowski and Mackay, 2011; Tremaroli and Bäckhed, 2012; LopezLegarrea et al., 2014). In vitro, SCFAs increase the production of anti-inflammatory cytokines, such as IL-10, and decrease production of proinflammatory cytokines, such as IL-1 $\beta$, IL-6, and TNF- $\alpha$ (Vinolo et al., 2011). Production of SCFAs also promotes transcription of the PTH1 gene, which encodes tryptophan hydroxylase, the rate-limiting enzyme of serotonin synthesis in the gut (Reigstad et al., 2015). SCFAs are also generally involved in G-protein signaling, modulation of cell signaling, cell-cell interactions, gene expression, immune function, and neurotransmitter synthesis and release (Nakao et al., 1998; Le Poul et al., 2003; Nguyen et al., 2007; Han et al., 2014; Nankova et al., 2014). Several physiological effects, including regulation of energy homeostasis, obesity, immune system functions, cancer, and cerebral function, as well as histone deacetylase (HDAC) inhibition, have been associated with butyrate (Koh et al., 2016). Specific host transporters and receptors are available for butyrate, and it is also used by colon cells as a source of energy through beta-oxidation (Stilling et al., 2016). Furthermore, acetate and propionate can be used by the liver for lipogenesis and gluconeogenesis, respectively (Janssen and Kersten, 2015). The potential for modulation of host metabolism and genetics by the gut microbiota suggests that the role of this factor warrants closer attention. This is especially true in IEMs in which metabolic pathways are originally altered, as the microbiome may act to reinforce metabolic pathways that are advantageous or disadvantageous to the host, with a direct impact on phenotype.

The evidence for a role of the composition of the human gut microbiota and its metabolites in health and illness becomes increasingly stronger (Sharon et al., 2014; Coleman and Nunes, 2016; Rooks and Garrett, 2016). Changes in the GI tract microbiota induce metabolic changes with systemic effects (Tremaroli and Bäckhed, 2012; OchoaRepáraz and Kasper, 2014; Sharon et al., 2014), and current research seeks to characterize microbiota-host interactions to elucidate the depth and breadth of this influence.
Some conditions, such as liver and bowel diseases and Clostridium difficile infection, are already being treated with microbiota-modifying therapies. These include probiotics, prebiotics, antibiotics, and fecal transplant (Sheth et al., 2016; Young, 2017). Probiotics are living microorganisms that, when administered at an appropriate concentration, can confer health benefits to the host, while prebiotics are indigestible components of foods that benefit the host by promoting growth or activity of a specific bacterial species or community in the colon. Fecal transplant is the administration of fecal matter from a healthy donor to a diseased individual, with the objective of restoring the typical microbial community of the healthy gut. These strategies can be used jointly or in isolation to restore the balance of the intestinal microbial community in the event of dysbiosis, which is any change to the composition of resident commensal communities relative to the community found in healthy individuals.

\section{Inborn Errors of Metabolism (IEM)}

IEMs are individually rare diseases, but as a group they are fairly common. Currently, more than 600 known human diseases are classified as IEMs (Alfadhel et al., 2016). Classically, IEMs are defined as a set of monogenic (single-gene) diseases that cause protein dysfunction, with partial or total loss of enzyme activity; however, IEMs can be pleiotropic, and may involve virtually any organ or system. Clinical onset may occur from even before birth up to adulthood (Sharer, 2011), and environmental triggers may be crucial determinants of individual phenotype (Lanpher et al., 2006). In an individual IEM, one primary metabolite flux is affected. In complex disease, however, a whole network of metabolite fluxes might be subtly altered to contribute to the overall phenotype. This concept of metabolic flux is essential in the translation of genetic and environmental factors into the phenotype or threshold for disease (Lanpher et al., 2006). Even a single metabolite defect can affect several secondary metabolic pathways, with a greater or lesser degree of environmental influence, to contribute to each patient's specific phenotype.

The treatment and management of IEMs are always individualized, based on each patient's diagnosis and phenotype, and there is broad heterogeneity even within each category (Argmann et al., 2016). Despite this heterogeneity in management approaches, the specific treatment usually falls into one of three classes: (I) enzyme replacement therapy, to replenish the deficient enzyme; (II) substrate reduction therapy; or (III) dietary treatment, although organ transplantation is also used in some cases (Ezgu, 2016). Additional non-specific treatment may be necessary, depending on the presence of comorbidities, such as neuropsychiatric disorders in PKU patients (Bilder et al., 2017), or renal and neurologic impairment in patients with tyrosinemia type I (Santra et al., 2008; Chinsky et al., 2017). Given the importance of diet to the microbiome, we will 
primarily address dietary therapy in this review, with a secondary focus on the importance of the microbiome in allogeneic hematopoietic stem-cell transplantation (HSCT).

Dietary treatment for IEMs may be employed as monotherapy or adjuvant therapy. Its purpose is to eliminate or reduce whichever toxic compound that accumulates in the body (Schwartz et al., 2008). However, this form of therapy has several limitations, including overload and/or deficiency of certain food groups and nutrients (Crenn and Maillot, 2007; Boyer et al., 2015). Theoretically, diets restricted or excessively rich in certain nutrients may prompt a state of intestinal dysbiosis with systemic effects, leading to malnutrition, obesity (Henao-Mejia et al., 2012), type 1 (Wen et al., 2008) or type 2 diabetes (Larsen et al., 2010), inflammatory bowel disease (Ashton et al., 2017; Geirnaert et al., 2017) and liver disease (Lee and Sokol, 2015), as well as a variety of disorders featuring an inflammatory component, symptoms of autism spectrum disorders (De Angelis et al., 2015), and even cancer (Jacqueline et al., 2017; Xu and Jiang, 2017). Studies seeking to identify the effects of dietary treatment and nutrient supplementation on the microbiome of patients with IEMs are still scarce. A summary of this research will be presented below and in Table 1.

Organ transplantation (mainly liver transplantation and HSCT) is also a treatment option for several IEMs (Sirrs et al., 2013; Boelens et al., 2014). Within this context, the microbiome was recently noted as a key factor in graft- $v s$. -host disease (GVHD). Acute GVHD is characterized by rupture of the intestinal barrier, caused by the conditioning regimen administered before HSCT and by leakage of microbe-associated molecular patterns (MAMPs, also known as pathogen-associated molecular patterns or PAMPs), particularly lipopolysaccharide (LPS). The proinflammatory response mounted against these molecules leads to systemic inflammation. Antibiotic treatment in the perioperative period of allogeneic HSCT has been associated with a higher likelihood of GVHD and lower odds of survival, which suggests a potentially pathogenic role of antibiotics through depletion of gut microbiome diversity. The finding that fecal transplant successfully treats GVHD by reconstituting the microbiota has reinforced this theory (Balmer et al., 2014; Melis et al., 2014; Kakihana et al., 2016; Rashidi et al., 2017; Routy et al., 2017; Spindelboeck et al., 2017). Efforts to characterize the influence of the microbiome in complications resulting from organ transplantation are paving the way for new avenues of treatment. Administration of Lactobacillus, for instance, appears to be a promising strategy for treatment of GVHD in allogeneic HSCT recipients, although the mechanism of action has yet to be fully understood (Staffas et al., 2017).

\section{Influence of the microbiome on the major organs affected by IEMs}

The features of IEMs are highly heterogeneous; however, the nervous system central (CNS) and liver, due to their high metabolic rate, are particularly susceptible to the effects of any metabolic defect (Sahoo et al., 2012). These organs are also closely related to microbiome activity, and a summary of on this matter can be found in Figure 1.

The microbiome has wide-ranging influence on the CNS, with probable effects on metabolism (Fu et al., 2015; Montagner et al., 2016), coordination (Sampson et al., 2016), mood (Slykerman et al., 2017), behavior (Tillisch et al., 2013), cognition (Steenbergen et al., 2015), temperature control (Chevalier et al., 2015), and sensation (Chiu et al., 2013). This influence may begin before birth, via the maternal microbiome (Rautava et al., 2012), and may be perpetuated throughout life, playing essential roles in the development of the blood-brain barrier (Braniste et al., 2014), maturation of the immune system (Chung et al., 2012), and also myelination of the prefrontal cortex (Hoban et al., 2016). Communication between the microbiome and the CNS is two-way, occurring both through metabolites and toxins produced by the bacterial community on the one hand, and via the immune, metabolic, nervous, and endocrine systems on the other (Powell et al., 2017). Over the years, disruption of the microbiome-brain-gut axis has been associated with various diseases. A breach in system homeostasis may occur at any point along this axis. Stressful situations affecting the brain, for instance, may affect the gut microbiome via the hypothalamic-pituitary-adrenal (HPA) axis, with repercussions for immune cell activity and bowel function (Moloney et al., 2014). Bacterial components, in turn, can stimulate secretion of proinflammatory cytokines from epithelial cells, dendritic cells, and macrophages. Knowingly, several neuropsychiatric disorders, including depression, anxiety, schizophrenia, and autism spectrum disorders, are associated with elevated circulating levels of proinflammatory cytokines (Liu et al., 2015a; Petra et al., 2015). In addition to these pathways, cerebral function can also be modulated by microbial metabolites capable of crossing the blood-brain barrier (Li and Zhou, 2016). Pierre and Pellerin (2005) reported that monocarboxylate transporters (MCTs), which transport lactate, pyruvate, ketone bodies, and other SCFAs, are widely expressed in cerebral tissue, and especially so in the cortex, hippocampus, striatum, and cerebellum (Pierre and Pellerin, 2005). In rats, $G$ protein-coupled receptors (GPCRs) activated by propionic acid (PPA) are also highly expressed in brain tissue (Bonini et al., 1997). Antibiotic therapy, which is commonly used in the treatment of some IEMs, depletes the microbiome and can affect levels of neuromodulatory substances (tryptophan, monoamines, and neuropeptides), thus influencing anxiety and cognition patterns (Desbonnet et al., 2015). 


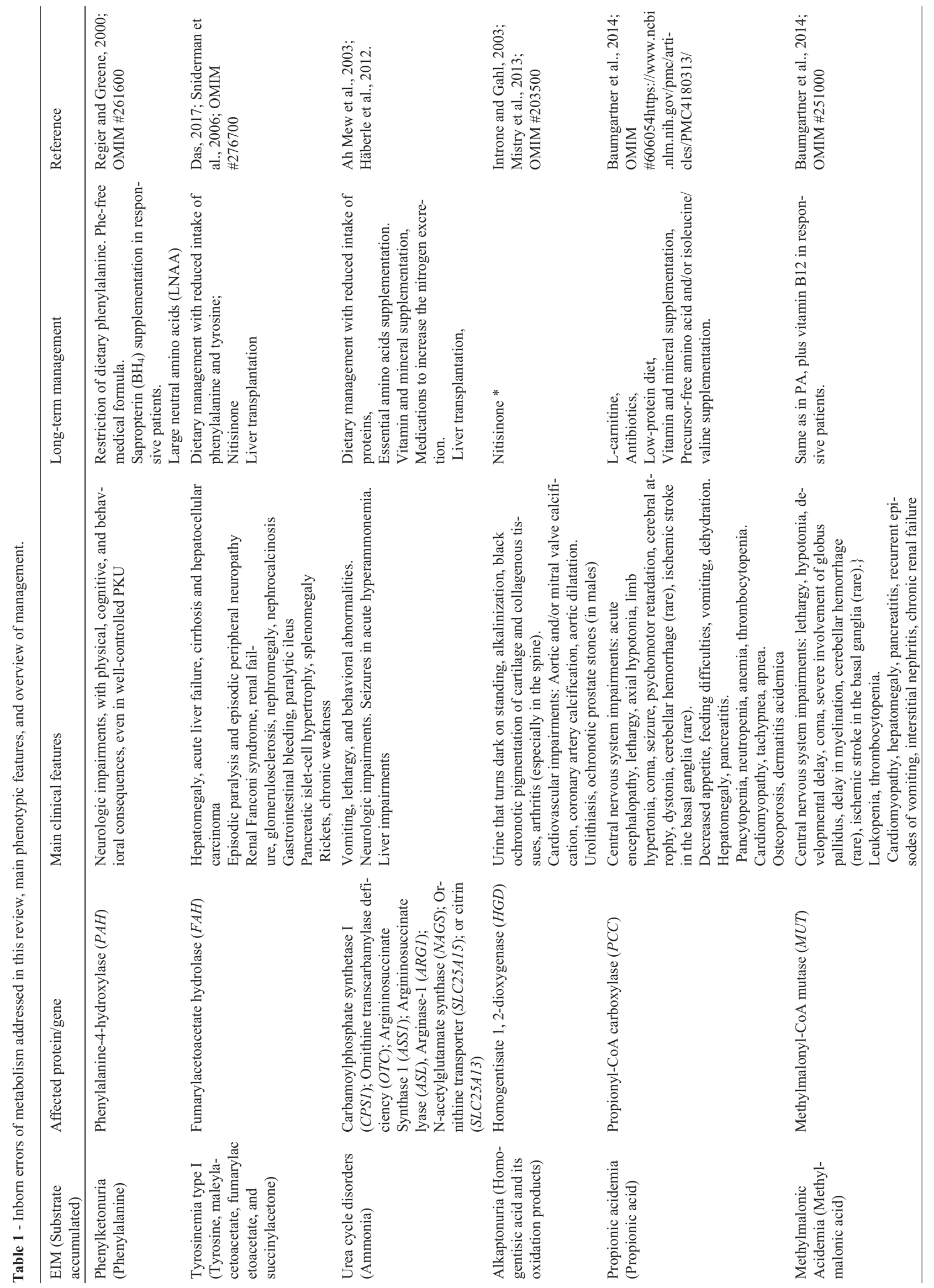


As evidence mounts for a systemic effect of the gut microbiome on the host, the liver has also been found to be affected by changes in the microbiome. In addition to its central role in intermediary metabolism (for instance, many enzymes affected by IEM are only expressed in liver) and bile secretion, the liver is the target organ of therapies for metabolic disorders (Brunetti-Pierri and Lee, 2005) and can also be considered a secondary lymphoid organ (Macpherson et al., 2016). Changes in liver physiology are probably caused primarily by DNA methylation processes, covalent histone modifications, and regulation of gene expression by non-coding RNA ( $n c \mathrm{RNA}$ ) (Macpherson et al., 2016). In addition to SCFAs, isothiocyanates and polyphenols are also produced by the microbiome, and all of these compounds have the potential to cause epigenetic changes. As the liver receives blood from the gut through the portal vein, it is susceptible to exposure to microbial byproducts that cross the intestinal barrier. In humans and non-human animals alike, whenever liver or bowel disease causes dysfunction of the barrier role played by these organs, there is a breakdown in mutualism between the host and the microbiome, which leads to systemic exposure to gut bacteria and increased immune activation (Chassaing et al., 2015). In these situations, the liver becomes a primary immune barrier that mediates host-microbiome mutualism (Balmer et al., 2014).

Hepatocytes are sensitive to microbial byproducts, and may trigger an inflammatory immune response with systemic effects: even exposure to low levels of LPS induces IFN- $\gamma$ overexpression and IL-10 underexpression in the liver in animal models of obesity, thus predisposing to the development of steatohepatitis (Yang et al., 1997). On the other hand, deletion of the flagellin receptor TLR5 in mouse hepatocytes has been shown to predispose to hepatic steatosis and fibrosis, as well as other features of the metabolic syndrome. In this study, antibiotic treatment was able to reverse steatosis and related aspects in TLR5 knockout mice, suggesting that mechanisms for clearance of microorganisms capable of gut-liver translocation is essential for maintenance of host systemic health, preventing the chronic inflammation induced by microbial pathogens (Etienne-Mesmin et al., 2016). Taking into account the important immune role of the liver, it makes sense that most patients with cirrhosis and severe liver failure die of sepsis, not of metabolic derangements (Leber et al., 2009), as many of these infections are caused by oral commensals or gut microbiota (Gustot et al., 2009). The dysbiosis state itself impulses inflammatory response and has potential for causing disease. The role of the microbiome in liver disorders is further supported by the efficiency of treating these conditions with probiotics, prebiotics, and antibiotics. Studying the microbiome, hence, may provide a better understanding of complex diseases and lay the groundwork for new therapies (Tilg et al., 2016). 


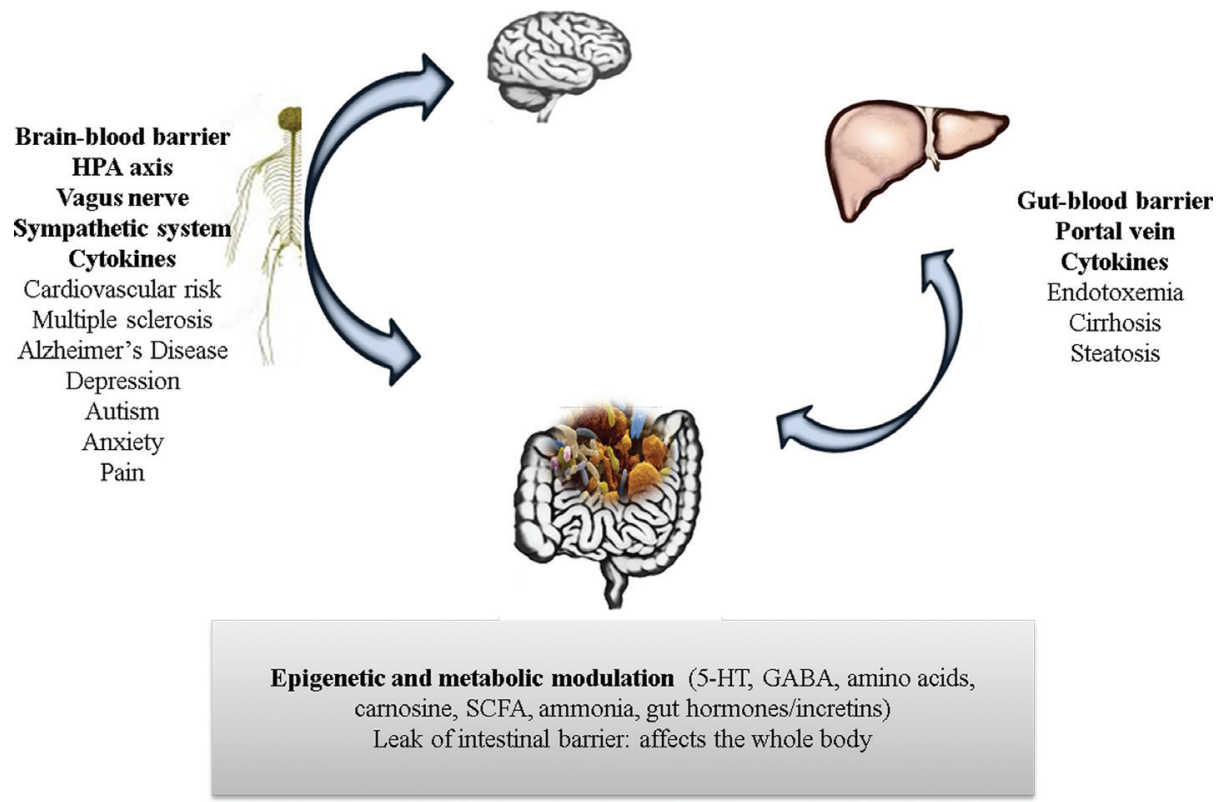

Figure 1 - Known effects of the gut microbiome on the main organs affected in an IEM. In bold are the ways by which the interactions occur. Below are the features related to the gut microbiota and the organs. The gut microbiome produces several metabolites and actively participates in the biosynthesis of vitamins and cofactors, metabolism of carbohydrates, proteins and lipids. The gut microbiota interacts with the whole body via the immune and endocrine systems. The two major organs affected in an IEM are the brain and the liver. In addition to the components of the immune and endocrine systems, the described gut-brain interactions also involve the brain-blood barrier, HPA axis, vagus nerve and the sympathetic system. This may predispose to several diseases, such as increased cardiovascular risk, multiple sclerosis, Alzheimer's disease, depression, autism, anxiety, and also can be related to pain. Interactions with the liver can occur via the portal vein, the gut-blood barrier, and can be involved in several hepatic diseases, most of them linked to endotoxemia.

\section{The microbiome and IEMs: the state of the art}

The gut microbiome plays roles in amino acid and carbohydrate metabolism, vitamin and cofactor biosynthesis, and production of SCFAs, in addition to influencing the physiology of the liver, brain, and GI tract, all of which are affected by IEMs. In light of the many important activities of this virtual metabolic organ and its vast impact on the host, some studies have considered the microbiome as a factor that interferes with organic homeostasis in the context of IEMs, and have sought to characterize possible interactions, both endogenous (genetic defect) and exogenous (treatment/diet), with host metabolic pathways, as well as the probable consequences of the presence or absence of specific bacteria and their metabolites on the human body.

Studies of the association between microbiome and IEMs have focused on aminoacidopathies (such as PKU, tyrosinemia, and alkaptonuria), organic acidemias (methylmalonic acidemia and propionic acidemia), and hemochromatosis. The main characteristics of the IEMs addressed in these studies, including their long-term management, are summarized in Table 2. Some possible effects of treatments of IEM on microbiome are showed in Figure 2.

The majority of studies on microbiome-IEM interactions has focused on PKU. One of the most thorough among such studies compared the microbiome of eight patients with PKU to that of 10 healthy individuals by analy- sis of the 16S rRNA gene. In this study, Pinheiro de Oliveira et al. (2016) demonstrated reduced abundance of bacteria in the families Clostridiaceae, Erysipelotrichaceae, and Lachnospiraceae, class Clostridiales, and genera Coprococcus, Dorea, Lachnospira, Odoribacter, Ruminococcus, and Veillonella in patients with PKU, as well as an increase in Prevotella, Akkermansia, and Peptostreptococcaceae populations. Their metabolic prediction was associated both with starch and glucose metabolism and with AA metabolism (Pinheiro de Oliveira et al., 2016). The authors raised the hypothesis that bacterial enrichment related to LPS biosynthesis, as observed in patients with PKU, might be associated with peripheral inflammation, as indicated by the proinflammatory circulating cytokine profile of these patients (Coakley et al., 2014). In the same study, the authors found a correlation between microbiotic profile and circulating levels of phenylalanine (Phe), which might indicate a relationship between these patients' microbiome, their treatment response, and their phenotype.

Focusing on the potential impacts of prebiotic treatment in individuals with PKU, a study reported by MacDonald et al. (2011) analyzed the effects of prebiotic oligosaccharides (scGOS/lcFOS) as an adjunct to the metabolic formula that forms the mainstay of PKU management. As breastfeeding is highly restricted in children with PKU, the authors theorized that a lack of the oligosaccharides present in breast milk might be associated with in- 


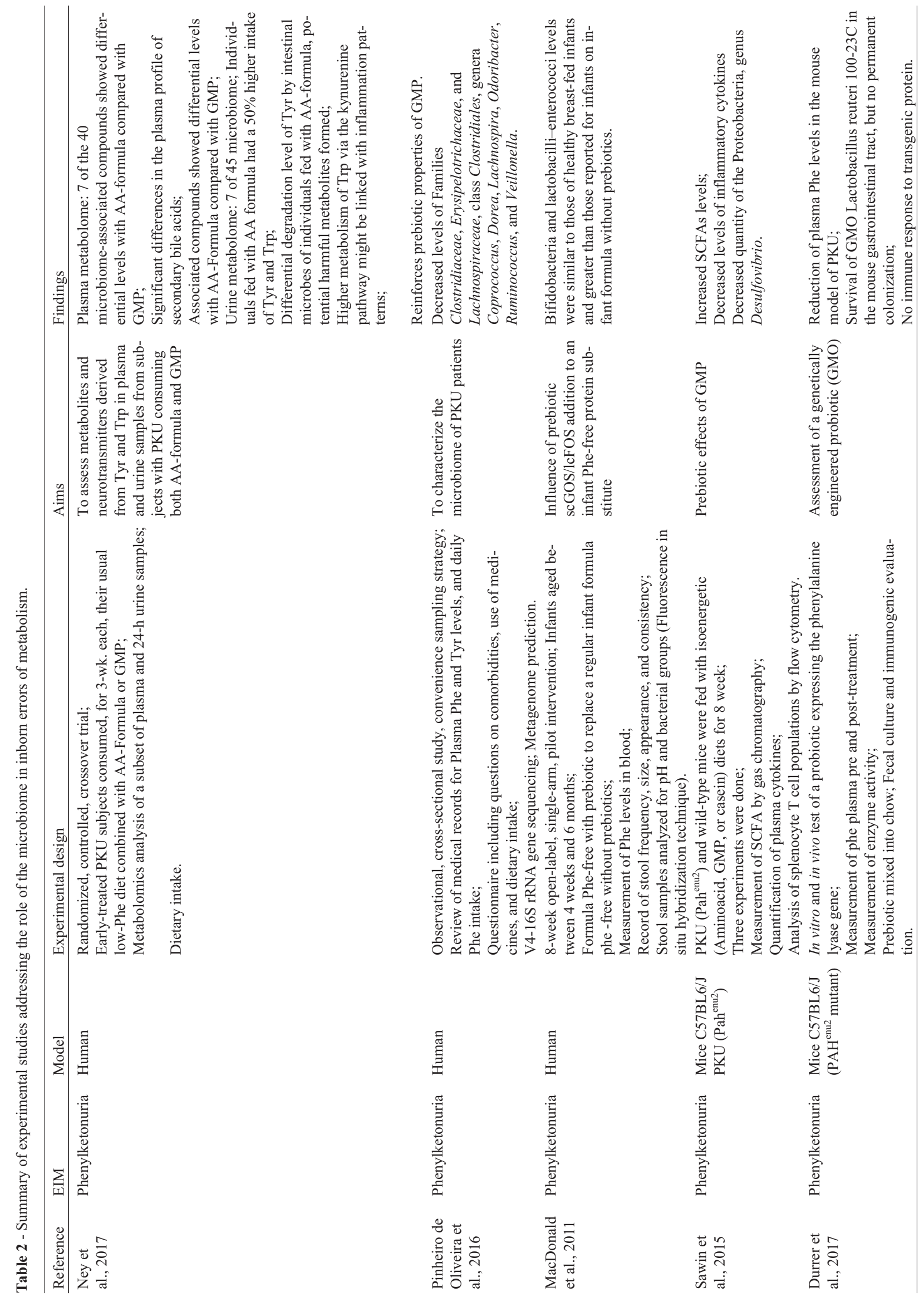




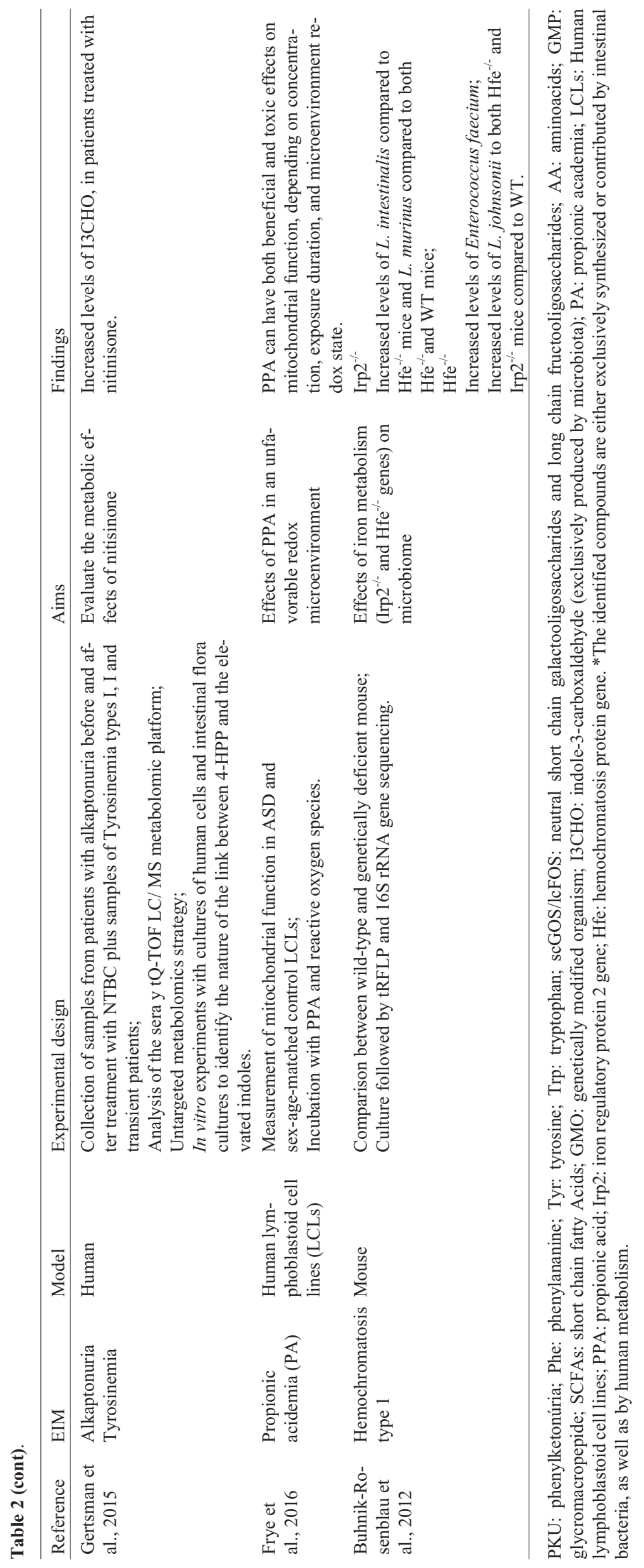



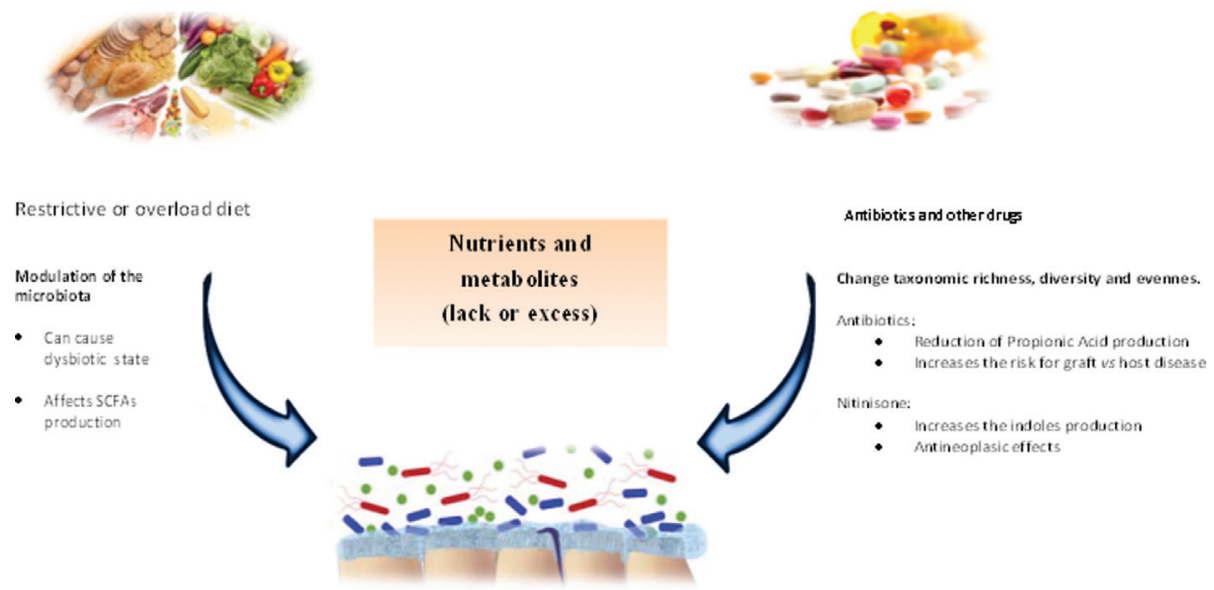

Figure 2 - Common treatments used in IEM and its effects over the microbiome. Diet is an important modulator of the microbiome, and also is a very common treatment for several IEMs. Diets with restriction or abundance of certain nutrients can cause a dysbiotic state, leading to an abnormal immune signaling (inflammation), leaking of gut-blood barrier, and breaking of the energetic balance of cells, with potential to affect the whole body. Antibiotics, on other hand, cause rapid and significant drops in taxonomic richness, diversity and evenness. This can bring benefits, as in the case of propionic/methylmalonic acidemia patients, by decreasing the levels of propionic/methylmalonic acid, or not, as in the case of organ transplants, once patients treated with antibiotics during the perioperative period had an increased risk for graft $v s$. host disease. Organ transplantation is a treatment for several IEMs. Other drugs used for treating this class of genetic disease can also affect the microbiome or metabolite production, like nitinisone, used in treatment of tyrosinemia type I, that raises the levels of indoles which in turn have antineoplasic effects.

creased fecal $\mathrm{pH}$ and reduced bifidobacterial populations, thus predisposing the patient to infections. Administration of probiotics might mitigate this problem. The experiment assessed the dominant bacterial groups and found that the administered prebiotic oligosaccharides were able to maintain bifidobacteria levels and low fecal $\mathrm{pH}$, without altering circulating levels of Phe. Despite the small sample size and lack of statistical power, these findings suggest that supplementing metabolic formula with prebiotics might be an interesting strategy in PKU, as the levels of Bifidobacteria and Lactobacilli-Enterococci at the end of the study were similar to those found in healthy children and higher than those reported in children who took the formula alone, without prebiotics. In the only patient who was previously receiving a diet without prebiotics, there was also a reduction in pathogens such as $C$. perfringens and $C$. difficile (group Clostridium histolyticum/lituseburense), E. coli, Shigella, Salmonella, and Klebsiella (subgroup Enterobacteriaceae) (MacDonald et al., 2011).

Also regarding prebiotics, recent years have been promising in terms of the use of glycomacropeptide (GMP) as a substitute for Phe-free AA formula in patients with PKU. GMP is highly glycosylated and, when pure, constitutes a natural protein source that lacks the AAs (Phe, tyrosine (Tyr), tryptophan (Trp), histidine, cysteine, arginine) involved in some IEMs, including PKU (Neelima et al., 2013). For now, human trials are seeking to ascertain the efficiency of GMP as a partial (50\% formula, $50 \%$ GMP) or total replacement for the Phe-free AA formula. In trials, the use of GMP had no significant impact on circulating Phe levels and was preferred by patients over the formula, as GMP is more palatable and, according to patients, provides greater satiety than a formula-based diet alone (Ney et al., 2016; Zaki et al., 2016). This could make GMP an option to increase treatment adherence.

When the urine and plasma metabolome of the individuals with PKU were compared within the groups fed with AA-formula or GMP, differences were found between the metabolite profile linked to the microbes. There were no differences between fasting plasma concentrations of the Tyr and Trp, but individuals fed with AA formula had a $50 \%$ higher intake of Tyr and Trp. This can be explained as a result of higher degradation by the intestinal microbes, raising the levels of microbiome-derived compounds from Tyr. Some of these compounds are potentially harmful. There was no differential degradation of Trp, but the metabolism of Trp via the kynurenine pathway was evidenced by higher levels of metabolites linked to this pathway and might be linked with inflammation patterns. Change in plasma profile of secondary bile acids, but not primary bile acids, supports the statement that there are alterations in the gut microbiome with ingestion of AA-formula and GMP, and reinforces the prebiotic proprieties of the GMP (Ney et al., 2017).

Although the effect of GMP on the human gut microbiome has yet to be studied, in mice, GMP was associated with control of Th2-type immune responses, increased Lactobacillus and Bifidobacterium populations in as little as three days after treatment (Jiménez et al., 2016), elevated levels of SCFAs and reduced levels of proinflammatory cytokines, and reduced Proteobacteria counts (genus Desulfovibrio) without affecting circulating Phe levels (Sawin et al., 2015). The genus Desulfovibrio is associated with production of hydrogen sulfate, a cytotoxic compound 
found at higher levels in patients with ulcerative colitis (Rowan et al., 2010).

Regarding disorders of tyrosine metabolism, Gertsman et al. (2015) described the metabolic effect of nitisinone (NTBC or 2-(2-nitro-4-fluoromethylbenzoyl)-1,3cyclohexanedione) in patients with alkaptonuria. Analysis of their metabolic profile showed that indole levels were increased in treated patients as compared with controls. Indoles play a key role in signaling pathways (as building blocks for melanin and serotonin) and intercellular communication, facilitate quorum sensing, and have been uniquely associated with dietary intake and microbial metabolism of tryptophan. Among the indoles found to be increased, indole-3-carboxaldehyde ( $\mathrm{I} 3 \mathrm{CHO})$ is produced exclusively by the microbiota, while the other two are produced by human cells (Gertsman et al., 2015). The authors stressed that the reduced form of $\mathrm{I} 3 \mathrm{CHO}$, indole-3-carbinol, a compound also found in cruciferous vegetables, is associated with the prevention of several neoplasms.

Animal experiments also suggest that genetic defects in the host may alter the composition of the gut microbiota, leading to dysbiosis due to a buildup of substances in the cells or lumen of the bowel (Buhnik-Rosenblau et al., 2012). This effect has been observed in hemochromatosis. Hemochromatosis is a disease caused by excess iron absorption by gut cells, which leads to iron overload. This usually becomes clinically detectable in adulthood and is damaging to many organs, including the liver, pancreas (causing diabetes), heart, and skin (Babitt and Lin, 2011). Mutations in the HFE gene account for the majority of cases of hereditary hemochromatosis, especially in individuals of Northern European descent (Barton, 2013). In a study of mice with mutations in two genes that encode proteins involved in regulation of iron homeostasis $\left(\mathrm{HFE}^{-/}\right.$and $\operatorname{Irp} 2^{-/}$), Buhnik-Rosenblau et al. (2012) found abnormalities particularly in resident populations of lactic-acid bacteria, both in $\operatorname{Irp} 2$-mutant and in $H F E$-mutant mice as compared to controls.

The gut microbiome produces several metabolites, including PPA, a SCFA implicated in several diseases. In autistic populations, the level of the phylum Firmicutes is increased and was largely attributable to Clostridia class with Ruminococcaceae and Lachnospiraceae families. The differences in Clostridia species in children with autism spectrum disorder include greater abundance of Clostridium clusters I, II, XI and C. bolteae (Finegold et al., 2002; Song et al., 2004; Parracho et al., 2005; Williams et al., 2011; Strati et al., 2017). Several Ruminococcaceae and Lachnospiraceae are known butyrate producers and may thus influence SCFA levels (Louis et al., 2010). So, the treatment with antibiotics can affect producers of SCFA. Some patients' symptoms improve transiently when antibiotics are administered (Sandler et al., 2000; Shaw 2010). Curiously, a similar effect is seen in patients with propionic acidemia, who can experience the same neuro- developmental complications seen in autism (Witters et al., 2016). Among the various roles played by PPA, it was recently reported to act as a modulator of mitochondrial function. In a study of autism and control cell lines, the effects of PPA depended not only on the concentration of the acid, but also on the level of reactive oxygen species (ROS) present, as ROS influence mitochondrial ability to use PPA as an energy source. Thus, PPA could have beneficial effects in individuals without mitochondrial dysfunction, and harmful effects in individuals with an unfavorable metabolic status and elevated levels of ROS (Frye et al., 2016). In methylmalonic acidemia, which shares several symptoms and management strategies with propionic acidemia, vitamin $B_{12}$ (cobalamin) is also used as treatment in responsive patients, in addition to antibiotics. This vitamin is synthesized by some gut bacteria, and is also a regulator of microbiome composition and function (Baumgartner et al., 2014; Degnan et al., 2014).

The microbiome can also be considered an exogenous source of tetrahydrobiopterin $\left(\mathrm{BH}_{4}\right)$, another important metabolite of gut bacteria. $\mathrm{BH}_{4}$ is a key cofactor for several regulatory enzymes, as Phenylalanine-4-hydroxylase, which catalyzes the conversion of L-phenylalanine to L-tyrosine. The $\mathrm{BH}_{4}$ has also been shown to improve working memory and cerebral activation (Christ et al., 2013). In rodents, $\mathrm{BH}_{4}$ production is age-dependent and is related to the presence of Actinobacteria in the bowel, especially Adlercreutzia equolifaciens and Microbacterium schleiferi. These same species have been identified in the human gut microbiome (Belik et al., 2017). Very little is known about the determinants of responsiveness to $\mathrm{BH}_{4}$ therapy and its effects on cerebral activity and cognition, but these effects are known to be multifactorial, as they vary across individuals with the same genotype (Pérez et al., 2005). The discovery that $\mathrm{BH}_{4}$ is naturally produced by gut microbiota has implications for translational medicine, as this cofactor is used in the treatment of some patients with PKU.

The long-term perspective is that elucidation of the metabolic role of the microbiota and identification of which species play these roles will pave the way for manipulating the microbiome, so that pathways beneficial to the host are stimulated, while those harmful to the host are inhibited. In this line, some authors have raised the hypothesis of using methanogenic bacteria normally present in the human bowel to control metabolites such as trimethylamine (TMA), bypassing the normal route of trimethylamine Noxide (TMAO) production as an intermediate for $\mathrm{CH}_{4}$ to an alternative pathway (Brugère et al., 2014). In the liver, deficiency in the pathway of TMA conversion into TMAO leads to trimethylaminuria, an IEM that causes strong body odor, impairing the patients' quality of life and interpersonal relations (Mackay et al., 2011). Diets rich in compounds such as phosphatidylcholine, choline, betaine, and L-carnitine generate TMA via the gut microbiota, which is 
then converted in TMAO by the liver. High levels of TMAO are associated with increased risk of cardiovascular disease in the general population (Wang et al., 2011; Koeth et al., 2013; Gregory et al., 2015; Liu et al., 2015b). Making the transition from theory into practice, administration of the probiotic Lactobacillus reuteri, engineered to express a phenylalanine lyase gene from the cyanobacteria Anabaena variabilis, successfully treated mice with PKU. Blood levels of Phe declined after the fourth day of treatment and remained low throughout the experiment, with no permanent colonization of the gut (Durrer et al., 2017), suggesting potential for modified probiotics in the treatment of IEMs.

The creation of genetically modified probiotics design especially to normalize defective metabolic pathways in the host is only one of the many potential advantages of microbiome research. IEMs are characterized by substantial variability in presentation, and genotype alone cannot explain patients' clinical pictures. The microbiome may contribute significantly to factors such as tolerance to certain nutrients and responsiveness to cofactors (and to treatment itself). Studying the microbiomes of patients with IEMs may provide valuable tools for clinical practice, both advancing our understanding of phenotypes and facilitating the development of new biomarkers and therapies.

\section{Main questions about microbioma and IEM and how to address them}

There are some important issues involved in the study of the human microbiome in IEM. First of all, most of the diseases that compound the IEM class are rare, and usually there are subclasses within the same IEM. This is the reason why the studies normally have a small number of participants. Second, the microbiome is mainly influenced by diet, and diet overload or restriction is one of most common treatments for IEM. This is one of reasons that make obtaining an adequate control group very difficult. Third, this class of diseases is derived of a metabolic genetic defect, and defects in a metabolic gene also affect the microbiome. So, if a dysbiotic state is observed in this group of patients will it reflect the genetic or the diet effect? Taken together, all the facts above make it very hard to obtain a homogeneous and statistically valid group of untreated patients and make difficult the comparison pre and post-treatment to verify if the altered microbiome is mainly affected by genetic or diet effects. Additional difficulty is added by the fact that several metabolic diseases, if untreated, can lead to severe impacts through life, so IEM patients should start to be treated as soon as possible.

Despite the difficulties, studying the patterns of the microbiome in groups of treated patients offers the possibility to evaluate the real impact of the genetic defect and diet on the microbiome. Patients need lifelong treatment, and the intragroup study of phenotype, microbiome and diet can be elucidative for some ancient questions that remain unknown. PKU patients, for instance, were studied in light of the microbiome by Pinheiro de Oliveira et al. (2016) (see Table 2). Even though not capable of answering the question if alteration comes from diet or genetics, a microbiome alteration correlated with Phe blood levels was observed. This is exciting data, due to the fact that it can help explain why some patients are more tolerant to Phe than others, despite having the same genotypes.

In an IEM, the genetic defect and the diet factors coexist, so the measure of macro- and micronutrients ingested is required. Diet has a strong impact on the microbiome, and in spite of patients having similar lines of treatment all over the world, the source of fibers, carbohydrates and proteins can vary geographically and/or culturally. For this reason, microbiome studies should not combine patients of geographically distinct regions or culture to raise the number of participants. Rather, these studies must be done locally and then, if methodologically possible, make comparisons that take into account the dietetic/cultural/geographic factors.

As detailed above, there are several other factors that can influence and be influenced by the microbiome. Important data as sex, age, body mass index, type of birth delivery, breast feeding (duration and transition to solid food), antibiotic and other drug usage, vitamin supplementation, as well as physical exercise, and other diseases (physical and/or mental) must be collected and also analyzed. All subjects included in studies that aim to characterize the microbiome of certain IEMs should be three years or older to avoid the period of drastic changes in microbiome composition due to the typical change in diet during this period. Given that the microbiome varies according to the stage of life and sex, and certain cultures can also exert some influence, the best way to avoid interference of age and sex is the sex-age-matched strategy.

Another useful strategy is based on experimental studies using animal models. This strategy is very important since animal models have less genetic variation and are maintained in a highly controlled environment (that includes diet and/or a germ-free environment). Also, a high the number of subjects can be easily obtained in such research. This is the better model for initial tests of genetically engineered probiotics and correlations with diseases caused by the genetic defect in the absence or presence of the treatment. This kind of study, besides not being capable of fully reproducing the human reality, can work to generate hypotheses and help to provide better strategies and comprehension of studies done in humans.

With the development of NGS tools, procedures are no longer the main limitation for human microbiome studies. Microbiome data is currently obtained by three different approaches: 1) by $16 \mathrm{~S}$ rRNA gene partial sequencing, 2) by whole DNA shotgun metagenomic sequencing, or 3 ) by metatranscriptomics (mRNA-seq), to access the active 
gene expression pattern For instance, the 16S rRNA gene sequencing method is largely used and has been the first choice method among researchers. Reasons for choosing this approach include the availability of a comprehensive database and scalability. Moreover, studies based in metatranscriptomics require a better control for sample collection to RNA/metabolites processing. Metagenomics, metatranscriptomics and all other "omics", and the associated bioinformatics techniques are allowing comparative analyses in an unprecedented way. All of these tools allow for testing a recent hypothesis related to the presence of a common set of microbial taxa universally present in healthy individuals (Turnbaugh et al., 2007), also known as microbial core. However large variations in the taxonomic composition observed in the human microbiome rapidly refute such a hypothesis (Bäckhed et al., 2012). Due to the well-known microbial functional redundancy in nature, an alternative hypothesis is the presence of a functional core represented by a set of metabolic functions that are performed by the microbiome within a particular habitat, but are not necessarily provided by the same organisms in different people (Shafquat et al., 2014). Still, studies devoted to better understand how deeply the microbiome can affect an organism with critical metabolic pathways that are naturally altered, are just in the early stages. Multidisciplinary efforts need to be done to aggregate modern techniques of sequencing and identification of metabolites that can lead to the phenotype or drug effect in question. Microbial sequencing alone will not be capable of explaining the phenotype, but is a fundamental tool in the understanding of the process. Additional techniques based on metabolomics analysis and RNA-seq, as well as gathering information about the immune system and SCFA levels can offer fundamental pieces of information in the process.

\section{Conclusions}

Studies on the microbiome in IEMs are scarce. The effects of the genetic defect itself and of treatment in IEMs, especially in the long term, have yet to be fully understood. As IEMs are commonly managed through dietary intervention (nutrient overload and/or restriction), dysbiosis is a possibility. This dysbiotic status would alter the patients' already compromised metabolic state even further, inducing or worsening abnormalities in secondary metabolic pathways, and thus contributing to phenotypic manifestations, especially liver and brain involvement. Dysbiosis can be treated with antibiotic therapy, dietary prebiotics, or fecal transplant, alone or in combination. The administration of probiotics engineered to at least partly meet the metabolic needs of the IEM-affected host has practically unexplored therapeutic potential and may constitute an intervention that is simple to administer, yet has a major impact on the patients' lives. Collectively, microbiome research in patients with IEMs can not only contribute significantly to our understanding of the pathophysiology of these diseases and to the development of new biomarkers and therapies, but also help to improve the long-term quality of life in affected patients.

\section{Acknowledgments}

The authors acknowledge the financial support of CAPES, FAPERGS and FIPE-HCPA.

\section{References}

Alfadhel M, Benmeakel M, Hossain MA, Al Mutairi F, Al Othaim A, Alfares AA, Al Balwi M, Alzaben A and Eyaid W (2016) Thirteen year retrospective review of the spectrum of inborn errors of metabolism presenting in a tertiary center in Saudi Arabia. Orphanet J Rare Dis 11:126.

Argmann CA, Houten SM, Zhu J and Schadt EE (2016) A next generation multiscale view of inborn errors of metabolism. Cell Metab 23:13-26.

Ashton JJ, Colquhoun CM, Cleary DW, Coelho T, Haggarty R, Mulder I, Batra A, Afzal NA, Beattie RM, Scott KP, et al. (2017) 16S sequencing and functional analysis of the fecal microbiome during treatment of newly diagnosed pediatric inflammatory bowel disease. Medicine (Baltimore) 96:e7347.

Babitt JL and Lin HY (2011) The molecular pathogenesis of hereditary hemochromatosis. Semin Liver Dis 31:280-292.

Bäckhed F, Fraser CM, Ringel Y, Sanders ME, Sartor RB, Sherman PM, Versalovic J, Young V and Finlay BB (2012) Defining a healthy human gut microbiome: Current concepts, future directions, and clinical applications. Cell Host Microbe 12:611-622.

Balmer ML, Slack E, de Gottardi A, Lawson MAE, Hapfelmeier S, Miele L, Grieco A, Van Vlierberghe H, Fahrner R, Patuto $\mathrm{N}$, et al. (2014) The liver may act as a firewall mediating mutualism between the host and its gut commensal microbiota. Sci Transl Med 6:237ra66.

Barton JC (2013) Hemochromatosis and iron overload: From bench to clinic. Am J Med Sci 346:403-412.

Baumgartner MR, Hörster F, Dionisi-Vici C, Haliloglu G, Karall D, Chapman KA, Huemer M, Hochuli M, Assoun M, Ballhausen D, et al. (2014) Proposed guidelines for the diagnosis and management of methylmalonic and propionic acidemia. Orphanet J Rare Dis 9:130.

Belik J, Shifrin Y, Arning E, Bottiglieri T, Pan J, Daigneault MC and Allen-Vercoe E (2017) Intestinal microbiota as a tetrahydrobiopterin exogenous source in $h p h-1$ mice. Sci Rep 7:39854.

Bilder DA, Kobori JA, Cohen-Pfeffer JL, Johnson EM, Jurecki ER and Grant ML (2017) Neuropsychiatric comorbidities in adults with phenylketonuria: A retrospective cohort study. Mol Genet Metab 121:1-8.

Boelens JJ, Orchard PJ and Wynn RF (2014) Transplantation in inborn errors of metabolism: current considerations and future perspectives. Br J Haematol 167:293-303.

Bonini JA, Anderson SM and Steiner DF (1997) Molecular cloning and tissue expression of a novel orphan $G$ proteincoupled receptor from rat lung. Biochem Biophys Res Commun 234:190-193.

Boyer SW, Barclay LJ and Burrage LC (2015) Inherited metabolic disorders: Aspects of chronic nutrition management. 
Nutr Clin Pract Off Publ Am Soc Parenter Enter Nutr 30:502-510.

Braniste V, Al-Asmakh M, Kowal C, Anuar F, Abbaspour A, Tóth M, Korecka A, Bakocevic N, Ng LG, Guan NL, et al. (2014) The gut microbiota influences blood-brain barrier permeability in mice. Sci Transl Med 6:263ra158.

Brugère JF, Borrel G, Gaci N, Tottey W, O'Toole PW and Malpuech-Brugère C (2014) Archaebiotics: Proposed therapeutic use of archaea to prevent trimethylaminuria and cardiovascular disease. Gut Microbes 5:5-10.

Brunetti-Pierri N and Lee B (2005) Gene therapy for inborn errors of liver metabolism. Mol Genet Metab 86:13-24.

Buhnik-Rosenblau K, Moshe-Belizowski S, Danin-Poleg Y and Meyron-Holtz EG (2012) Genetic modification of iron metabolism in mice affects the gut microbiota. Biometals Int $\mathrm{J}$ Role Met Ions Biol Biochem Med 25:883-892.

Cani PD, Possemiers S, Van de Wiele T, Guiot Y, Everard A, Rottier O, Geurts L, Naslain D, Neyrinck A, Lambert DM, et al. (2009) Changes in gut microbiota control inflammation in obese mice through a mechanism involving GLP-2-driven improvement of gut permeability. Gut 58:1091-1103.

Chassaing B, Koren O, Goodrich JK, Poole AC, Srinivasan S, Ley RE and Gewirtz AT (2015) Dietary emulsifiers impact the mouse gut microbiota promoting colitis and metabolic syndrome. Nature 519:92-96.

Chevalier C, Stojanovic O, Colin DJ, Suarez-Zamorano N, Tarallo V, Veyrat-Durebex C, Rigo D, Fabbiano S, Stevanovic A, Hagemann S, et al. (2015) Gut Microbiota Orchestrates Energy Homeostasis during Cold. Cell 163:1360-1374.

Chinsky JM, Singh R, Ficicioglu C, van Karnebeek CDM, Grompe M, Mitchell G, Waisbren SE, Gucsavas-Calikoglu M, Wasserstein MP, Coakley K, et al. (2017) Diagnosis and treatment of tyrosinemia type I: a US and Canadian consensus group review and recommendations. Genet Med 19:1380

Chiu IM, Heesters BA, Ghasemlou N, Von Hehn CA, Zhao F, Tran J, Wainger B, Strominger A, Muralidharan S, Horswill AR, et al. (2013) Bacteria activate sensory neurons that modulate pain and inflammation. Nature 501:52-57.

Cho I and Blaser MJ (2012) The Human Microbiome: at the interface of health and disease. Nat Rev Genet 13:260-270.

Christ SE, Moffitt AJ, Peck D and White DA (2013) The effects of tetrahydrobiopterin $(\mathrm{BH} 4)$ treatment on brain function in individuals with phenylketonuria. NeuroImage Clin 3:539-547.

Chung H, Pamp SJ, Hill JA, Surana NK, Edelman SM, Troy EB, Reading NC, Villablanca EJ, Wang S, Mora JR, et al. (2012) Gut immune maturation depends on colonization with a host-specific microbiota. Cell 149:1578-1593.

Coakley K, Douglas T and Singh R (2014) Phenylketonuria is a condition of inflammation associated with high BMI and low bone turnover (1034.2) FASEB J 28:1034.2.

Coleman OI and Nunes T (2016) Role of the microbiota in colorectal cancer: Updates on microbial associations and therapeutic implications. BioResearch Open Access 5:279-288.

Cotillard A, Kennedy SP, Kong LC, Prifti E, Pons N, Le Chatelier E, Almeida M, Quinquis B, Levenez F, Galleron N, et al. (2013) Dietary intervention impact on gut microbial gene richness. Nature 500:585-588.
Crenn P and Maillot F (2007) Principes et contraintes des régimes au cours des maladies neurométaboliques chez l'adulte. Rev Neurol (Paris) 163:936-941.

Cummings JH, Pomare EW, Branch WJ, Naylor CP and Macfarlane GT (1987) Short chain fatty acids in human large intestine, portal, hepatic and venous blood. Gut 28:1221-1227.

Dabrowska K and Witkiewicz W (2016) Correlations of host genetics and gut microbiome composition. Front Microbiol 2016:1357

Das AM (2017) Clinical utility of nitisinone for the treatment of hereditary tyrosinemia type-1 (HT-1). Appl Clin Genet $10: 43-48$

David LA, Maurice CF, Carmody RN, Gootenberg DB, Button JE, Wolfe BE, Ling AV, Devlin AS, Varma Y, Fischbach MA, et al. (2014) Diet rapidly and reproducibly alters the human gut microbiome. Nature 505:559-563.

De Angelis M, Francavilla R, Piccolo M, De Giacomo A and Gobbetti M (2015) Autism spectrum disorders and intestinal microbiota. Gut Microbes 6:207-213.

De Filippo C, Cavalieri D, Di Paola M, Ramazzotti M, Poullet JB, Massart S, Collini S, Pieraccini G and Lionetti P (2010) Impact of diet in shaping gut microbiota revealed by a comparative study in children from Europe and rural Africa. Proc Natl Acad Sci U S A 107:14691-14696.

Degnan PH, Taga ME and Goodman AL (2014) Vitamin B12 as a modulator of gut microbial ecology. Cell Metab 20:769-778.

Desbonnet L, Clarke G, Traplin A, O'Sullivan O, Crispie F, Moloney RD, Cotter PD, Dinan TG and Cryan JF (2015) Gut microbiota depletion from early adolescence in mice: Implications for brain and behaviour. Brain Behav Immun 48:165-173.

Donaldson GP, Lee SM and Mazmanian SK (2016) Gut biogeography of the bacterial microbiota. Nat Rev Microbiol $14: 20-32$.

Durrer KE, Allen MS and Hunt von Herbing I (2017) Genetically engineered probiotic for the treatment of phenylketonuria (PKU); assessment of a novel treatment in vitro and in the PAHenu2 mouse model of PKU. PLoS One 12:e0176286.

Etienne-Mesmin L, Vijay-Kumar M, Gewirtz AT and Chassaing B (2016) Hepatocyte Toll-like Receptor 5 promotes bacterial clearance and protects mice against high-fat diet-induced liver disease. Cell Mol Gastroenterol Hepatol 2:584-604.

Ezgu F (2016) Inborn Errors of Metabolism. Adv Clin Chem 73:195-250.

Finegold SM, Molitoris D, Song Y, Liu C, Vaisanen ML, Bolte E, McTeague M, Sandler R, Wexler H, Marlowe EM, et al. (2002) Gastrointestinal microflora studies in late-onset autism. Clin Infect Dis 35:S6-S16.

Frye RE, Rose S, Chacko J, Wynne R, Bennuri SC, Slattery JC, Tippett M, Delhey L, Melnyk S, Kahler SG, et al. (2016) Modulation of mitochondrial function by the microbiome metabolite propionic acid in autism and control cell lines. Transl Psychiatry 6:e927.

Fu J, Bonder MJ, Cenit MC, Tigchelaar EF, Maatman A, Dekens JAM, Brandsma E, Marczynska J, Imhann F, Weersma RK, et al. (2015) The gut microbiome contributes to a substantial proportion of the variation in blood lipids. Circ Res 117:817-824. 
Geirnaert A, Calatayud M, Grootaert C, Laukens D, Devriese S, Smagghe G, Vos MD, Boon N and de Wiele TV (2017) Butyrate-producing bacteria supplemented in vitro to Crohn's disease patient microbiota increased butyrate production and enhanced intestinal epithelial barrier integrity. Sci Rep $7: 11450$.

Gertsman I, Gangoiti JA, Nyhan WL and Barshop BA (2015) Perturbations of tyrosine metabolism promote the indolepyruvate pathway via tryptophan in host and microbiome. Mol Genet Metab 114:431-437.

Gill SR, Pop M, DeBoy RT, Eckburg PB, Turnbaugh PJ, Samuel BS, Gordon JI, Relman DA, Fraser-Liggett CM and Nelson KE (2006) Metagenomic analysis of the human distal gut microbiome. Science 312:1355-1359.

Goodrich JK, Davenport ER, Waters JL, Clark AG and Ley RE (2016) Cross-species comparisons of host genetic associations with the microbiome. Science 352:532-535.

Gregory JC, Buffa JA, Org E, Wang Z, Levison BS, Zhu W, Wagner MA, Bennett BJ, Li L, DiDonato JA, et al. (2015) Transmission of atherosclerosis susceptibility with gut microbial transplantation. J Biol Chem 290:5647-5660.

Grenham S, Clarke G, Cryan JF and Dinan TG (2011) Brain-gut-microbe communication in health and disease. Front Physiol 2011:94.

Gustot T, Durand F, Lebrec D, Vincent JL and Moreau R (2009) Severe sepsis in cirrhosis. Hepatol Baltim $\mathrm{Md}$ 50:2022-2033.

Häberle J, Boddaert N, Burlina A, Chakrapani A, Dixon M, Huemer M, Karall D, Martinelli D, Crespo PS, Santer R, et al. (2012) Suggested guidelines for the diagnosis and management of urea cycle disorders. Orphanet J Rare Dis 7:32.

Han A, Sung YB, Chung SY and Kwon MS (2014) Possible additional antidepressant-like mechanism of sodium butyrate: targeting the hippocampus. Neuropharmacology 81:292-302.

Henao-Mejia J, Elinav E, Jin C, Hao L, Mehal WZ, Strowig T, Thaiss CA, Kau AL, Eisenbarth SC, Jurczak MJ, et al. (2012) Inflammasome-mediated dysbiosis regulates progression of NAFLD and obesity. Nature 482:179-185.

Hiergeist A, Gläsner J, Reischl U and Gessner A (2015) Analyses of intestinal microbiota: Culture vs. sequencing. ILAR J $56: 228-240$.

Hoban AE, Stilling RM, Ryan FJ, Shanahan F, Dinan TG, Claesson MJ, Clarke G and Cryan JF (2016) Regulation of prefrontal cortex myelination by the microbiota. Transl Psychiatry 6:e774.

Human Microbiome Project Consortium (2012) Structure, function and diversity of the healthy human microbiome. Nature 486:207-214.

Jacqueline C, Brazier L, Faugère D, Renaud F, Thomas F and Roche B (2017) Can intestinal microbiota be associated with non-intestinal cancers? Sci Rep 7:12722.

Janssen AWF and Kersten S (2015) The role of the gut microbiota in metabolic health. FASEB J 29:3111-3123.

Jiménez M, Cervantes-García D, Muñoz YH, García A, Haro LM and Salinas E (2016) Novel mechanisms underlying the therapeutic effect of glycomacropeptide on allergy: Change in gut microbiota, upregulation of TGF- $\beta$, and inhibition of mast cells. Int Arch Allergy Immunol 171:217-226.

Kakihana K, Fujioka Y, Suda W, Najima Y, Kuwata G, Sasajima $\mathrm{S}$, Mimura I, Morita H, Sugiyama D, Nishikawa $\mathrm{H}$, et al.
(2016) Fecal microbiota transplantation for patients with steroid-resistant acute graft- $v s$. -host disease of the gut. Blood 128:2083-2088.

Kashtanova DA, Popenko AS, Tkacheva ON, Tyakht AB, Alexeev DG and Boytsov SA (2016) Association between the gut microbiota and diet: Fetal life, early childhood, and further life. Nutrition 32:620-627.

Koeth RA, Wang Z, Levison BS, Buffa JA, Org E, Sheehy BT, Britt EB, Fu X, Wu Y, Li L, et al. (2013) Intestinal microbiota metabolism of L-carnitine, a nutrient in red meat, promotes atherosclerosis. Nat Med 19:576-585.

Koh A, De Vadder F, Kovatcheva-Datchary P and Bäckhed F (2016) From dietary fiber to host physiology: Short-chain fatty acids as key bacterial metabolites. Cell 165:1332-1345.

Lanpher B, Brunetti-Pierri N and Lee B (2006) Inborn errors of metabolism: The flux from Mendelian to complex diseases. Nat Rev Genet 7:449-460.

Larsen N, Vogensen FK, Berg FWJ van den, Nielsen DS, Andreasen AS, Pedersen BK, Al-Soud WA, Sørensen SJ, Hansen LH and Jakobsen M (2010) Gut microbiota in human adults with type 2 diabetes differs from non-diabetic adults. PLoS One 5:e9085.

Le Poul E, Loison C, Struyf S, Springael JY, Lannoy V, Decobecq ME, Brezillon S, Dupriez V, Vassart G, Van Damme J, et al. (2003) Functional characterization of human receptors for short chain fatty acids and their role in polymorphonuclear cell activation. J Biol Chem 278:25481-25489.

Leber B, Mayrhauser U, Rybczynski M and Stadlbauer V (2009) Innate immune dysfunction in acute and chronic liver disease. Wien Klin Wochenschr 121:732-744.

Lee WS and Sokol RJ (2015) Intestinal microbiota, lipids and the pathogenesis of intestinal failure-associated liver disease. J Pediatr 167:519-526.

Li Q and Zhou JM (2016) The microbiota-gut-brain axis and its potential therapeutic role in autism spectrum disorder. Neuroscience 324:131-139.

Liu J, Sun J, Wang F, Yu X, Ling Z, Li H, Zhang H, Jin J, Chen W, Pang M, et al. (2015a) Neuroprotective effects of Clostridium butyricum against vascular dementia in mice via metabolic butyrate. BioMed Res Int 2015:412946

Liu TX, Niu HT and Zhang SY (2015b) Intestinal microbiota metabolism and atherosclerosis. Chin Med J 128:2805-2811.

Lloyd-Price J, Abu-Ali G and Huttenhower C (2016) The healthy human microbiome. Genome Med 8:51.

Lopez-Legarrea P, Fuller NR, Zulet MA, Martinez JA and Caterson ID (2014) The influence of Mediterranean, carbohydrate and high protein diets on gut microbiota composition in the treatment of obesity and associated inflammatory state. Asia Pac J Clin Nutr 23:360-368.

Louis P, Young P, Holtrop G and Flint HJ (2010) Diversity of human colonic butyrate-producing bacteria revealed by analysis of the butyryl-CoA:acetate CoA-transferase gene. Environ Microbiol 12:304-314.

MacDonald A, Cochrane B, Wopereis H and Loveridge N (2011) Specific prebiotics in a formula for infants with Phenylketonuria. Mol Genet Metab 104(Suppl):S55-S59.

Mackay RJ, McEntyre CJ, Henderson C, Lever M and George PM (2011) Trimethylaminuria: Causes and diagnosis of a socially distressing condition. Clin Biochem Rev 32:33-43. 
Macpherson AJ, Heikenwalder M and Ganal-Vonarburg SC (2016) The liver at the nexus of host-microbial interactions. Cell Host Microbe 20:561-571.

Madigan MT, Martinko JM and Brock TD (2006) Brock Biology of Microorganisms. Pearson Prentice Hall, Nova Jersey, 992 p.

Marchesi JR and Ravel J (2015) The vocabulary of microbiome research: A proposal. Microbiome 3:31.

Martínez I, Stegen JC, Maldonado-Gómez MX, Eren AM, Siba PM, Greenhill AR and Walter J (2015) The gut microbiota of rural Papua New Guineans: Composition, diversity patterns, and ecological processes. Cell Rep 11:527-538. d

Maslowski KM and Mackay CR (2011) Diet, gut microbiota and immune responses. Nat Immunol 12:5-9.

Maukonen J and Saarela M (2015) Human gut microbiota: does diet matter? Proc Nutr Soc 74:23-36.

Mayer EA, Knight R, Mazmanian SK, Cryan JF and Tillisch K (2014) Gut microbes and the Bbrain: Paradigm shift in neuroscience. J Neurosci 34:15490-15496.

Melis D, Della Casa R, Balivo F, Minopoli G, Rossi A, Salerno M, Andria G and Parenti G (2014) Involvement of endocrine system in a patient affected by glycogen storage disease $1 \mathrm{~b}$ : speculation on the role of autoimmunity. Ital J Pediatr 40:30.

Mistry JB, Bukhari M and Taylor AM (2013) Alkaptonuria. Rare Dis $1: \mathrm{e} 27475$.

Moloney RD, Desbonnet L, Clarke G, Dinan TG and Cryan JF (2014) The microbiome: Stress, health and disease. Mamm Genome 5:49-74.

Montagner A, Korecka A, Polizzi A, Lippi Y, Blum Y, Canlet C, Tremblay-Franco M, Gautier-Stein A, Burcelin R, Yen YC, et al. (2016) Hepatic circadian clock oscillators and nuclear receptors integrate microbiome-derived signals. Sci Rep 6:20127.

Nakao S, Moriya Y, Furuyama S, Niederman R and Sugiya H (1998) Propionic acid stimulates superoxide generation in human neutrophils. Cell Biol Int 22:331-337.

Nankova BB, Agarwal R, MacFabe DF and La Gamma EF (2014) Enteric bacterial metabolites propionic and butyric acid modulate gene expression, including CREB-dependent catecholaminergic neurotransmission, in PC12 cells-possible relevance to autism spectrum disorders. PLoS One 9:e103740.

Neelima, Sharma R, Rajput YS and Mann B (2013) Chemical and functional properties of glycomacropeptide (GMP) and its role in the detection of cheese whey adulteration in milk: a review. Dairy Sci Technol 93:21-43.

Ney DM, Stroup BM, Clayton MK, Murali SG, Rice GM, Rohr F and Levy HL (2016) Glycomacropeptide for nutritional management of phenylketonuria: a randomized, controlled, crossover trial. Am J Clin Nutr 104:334-345.

Ney DM, Murali SG, Stroup BM, Nair N, Sawin EA, Rohr F and Levy HL (2017) Metabolomic changes demonstrate reduced bioavailability of tyrosine and altered metabolism of tryptophan via the kynurenine pathway with ingestion of medical foods in phenylketonuria. Mol Genet Metab 121:96-103.

Nguyen NHT, Morland C, Gonzalez SV, Rise F, Storm-Mathisen J, Gundersen V and Hassel B (2007) Propionate increases neuronal histone acetylation, but is metabolized oxidatively by glia. Relevance for propionic acidemia. J Neurochem 101:806-814.
Ochoa-Repáraz J and Kasper LH (2014) Gut microbiome and the risk factors in central nervous system autoimmunity. FEBS Lett 588:4214-4222.

Odamaki T, Kato K, Sugahara H, Hashikura N, Takahashi S, Xiao J, Abe F and Osawa R (2016) Age-related changes in gut microbiota composition from newborn to centenarian: a cross-sectional study. BMC Microbiol 16:90.

Omran YA and Aziz Q (2014) The Brain-Gut Axis in Health and Disease. In: Lyte M and Cryan JF (eds) Microbial Endocrinology: The Microbiota-Gut-Brain Axis in Health and Disease. Springer, New York, pp 135-153.

Oriach CS, Robertson RC, Stanton C, Cryan JF and Dinan TG (2016) Food for thought: The role of nutrition in the microbiota-gut-brain axis. Clin Nutr Exp 6:25-38.

Ottman N, Smidt H, de Vos WM and Belzer C (2012) The function of our microbiota: Who is out there and what do they do? Front Cell Infect Microbiol 2:104.

Parracho HMRT, Bingham MO, Gibson GR and McCartney AL (2005) Differences between the gut microflora of children with autistic spectrum disorders and that of healthy children. J Med Microbiol 54:987-991.

Pérez B, Desviat LR, Gómez-Puertas P, Martínez A, Stevens RC and Ugarte M (2005) Kinetic and stability analysis of PKU mutations identified in BH4-responsive patients. Mol Genet Metab 86(Suppl 1):S11-S16.

Petra AI, Panagiotidou S, Hatziagelaki E, Stewart JM, Conti P and Theoharides TC (2015) Gut-microbiota-brain axis and its effect on neuropsychiatric disorders with suspected immune dysregulation. Clin Ther 37:984-995.

Pierre K and Pellerin L (2005) Monocarboxylate transporters in the central nervous system: distribution, regulation and function. J Neurochem 94:1-14.

Pinheiro de Oliveira F, Mendes RH, Dobbler PT, Mai V, Pylro VS, Waugh SG, Vairo F, Refosco LF, Roesch LFW and Schwartz IVD (2016) Phenylketonuria and gut microbiota: A controlled study based on next-generation sequencing. PloS One 11:e0157513.

Powell N, Walker MM and Talley NJ (2017) The mucosal immune system: Master regulator of bidirectional gut-brain communications. Nat Rev Gastroenterol Hepatol 14:143-159.

Rashidi A, Khoruts A and Weisdorf DJ (2017) Infection followed by graft- $v s$. -host disease: Pathogenic role of antibiotics. Biol Blood Marrow Transplant 23:1038-1039.

Rautava S, Kainonen E, Salminen S and Isolauri E (2012) Maternal probiotic supplementation during pregnancy and breastfeeding reduces the risk of eczema in the infant. J Allergy Clin Immunol 130:1355-1360.

Reigstad CS, Salmonson CE, Rainey JF, Szurszewski JH, Linden DR, Sonnenburg JL, Farrugia G and Kashyap PC (2015) Gut microbes promote colonic serotonin production through an effect of short-chain fatty acids on enterochromaffin cells. FASEB J 29:1395-1403.

Rooks MG and Garrett WS (2016) Gut microbiota, metabolites and host immunity. Nat Rev Immunol 16:341-352.

Routy B, Letendre C, Enot D, Chénard-Poirier M, Mehraj V, Séguin NC, Guenda K, Gagnon K, Woerther PL, Ghez D, et al. (2017) The influence of gut-decontamination prophylactic antibiotics on acute graft- $v s$. -host disease and survival following allogeneic hematopoietic stem cell transplantation. Oncoimmunology 6:e1258506. 
Rowan F, Docherty NG, Murphy M, Murphy B, Calvin Coffey J and O'Connell PR (2010) Desulfovibrio bacterial species are increased in ulcerative colitis. Dis Colon Rectum 53:1530-1536.

Roy CC, Kien CL, Bouthillier L and Levy E (2006) Short-chain fatty acids: Ready for prime time? Nutr Clin Pract 21:351-366.

Sahoo S, Franzson L, Jonsson JJ and Thiele I (2012) A compendium of inborn errors of metabolism mapped onto the human metabolic network. Mol Biosyst 8:2545-2558.

Sampson TR, Debelius JW, Thron T, Janssen S, Shastri GG, Ilhan ZE, Challis C, Schretter CE, Rocha S, Gradinaru V, et al. (2016) Gut microbiota regulate motor deficits and neuroinflammation in a model of Parkinson's disease. Cell 167:1469-1480.e12.

Sandler RH, Finegold SM, Bolte ER, Buchanan CP, Maxwell AP, Väisänen ML, Nelson MN and Wexler HM (2000) Shortterm benefit from oral vancomycin treatment of regressive-onset autism. J Child Neurol 15:429-435.

Santra S, Preece MA, Hulton SA and McKiernan PJ (2008) Renal tubular function in children with tyrosinaemia type I treated with nitisinone. J Inherit Metab Dis 31:399-402.

Sawin EA, De Wolfe TJ, Aktas B, Stroup BM, Murali SG, Steele JL and Ney DM (2015) Glycomacropeptide is a prebiotic that reduces Desulfovibrio bacteria, increases cecal shortchain fatty acids, and is anti-inflammatory in mice. Am J Physiol Gastrointest Liver Physiol 309:G590-601.

Schwartz IV, Souza CFM and Giugliani R (2008) Treatment of inborn errors of metabolism. J Pediatr 84:S8-S19.

Segata N, Izard J, Waldron L, Gevers D, Miropolsky L, Garrett WS and Huttenhower C (2011) Metagenomic biomarker discovery and explanation. Genome Biol 12:R60.

Sender R, Fuchs S and Milo R (2016) Revised estimates for the number of human and bacteria cells in the body. PLoS Biol 14:e1002533.

Shafquat A, Joice R, Simmons SL and Huttenhower C (2014) Functional and phylogenetic assembly of microbial communities in the human microbiome. Trends Microbiol 22:261-6

Sharer JD (2011) An overview of biochemical genetics. Curr Protoc Hum Genet Chapter 17:17.1.

Sharon G, Garg N, Debelius J, Knight R, Dorrestein PC and Mazmanian SK (2014) Specialized metabolites from the microbiome in health and disease. Cell Metab 20:719-730.

Shaw W (2010) Increased urinary excretion of a 3-(3-hydroxyphenyl)-3-hydroxypropionic acid (HPHPA), an abnormal phenylalanine metabolite of Clostridia spp. in the gastrointestinal tract, in urine samples from patients with autism and schizophrenia. Nutr Neurosci 13:135-143.

Sheth RU, Cabral V, Chen SP and Wang HH (2016) Manipulating bacterial communities by in situ microbiome engineering. Trends Genet 32:189-200.

Sirrs SM, Faghfoury H, Yoshida EM and Geberhiwot T (2013) Barriers to transplantation in adults with inborn errors of metabolism. JIMD Rep 8:139-144.

Slykerman RF, Hood F, Wickens K, Thompson JMD, Barthow C, Murphy R, Kang J, Rowden J, Stone P, Crane J, et al. (2017) Effect of Lactobacillus rhamnosus HN001 in pregnancy on postpartum symptoms of depression and anxiety: A randomised double-blind placebo-controlled trial. EBioMedicine 24:159-165.
Song Y, Liu C and Finegold SM (2004) Real-Time PCR auantitation of Clostridia in feces of autistic children. Appl Environ Microbiol 70:6459-6465.

Sonnenburg ED and Sonnenburg JL (2014) Starving our microbial self: The deleterious consequences of a diet deficient in microbiota-accessible carbohydrates. Cell Metab 20:779-786.

Spindelboeck W, Schulz E, Uhl B, Kashofer K, Aigelsreiter A, Zinke-Cerwenka W, Mulabecirovic A, Kump PK, Halwachs B, Gorkiewicz G, et al. (2017) Repeated fecal microbiota transplantations attenuate diarrhea and lead to sustained changes in the fecal microbiota in acute, refractory gastrointestinal graft- $v s$. host-disease. Haematologica 102:e210-e213.

Staffas A, Burgos da Silva M and van den Brink MRM (2017) The intestinal microbiota in allogeneic hematopoietic cell transplant and graft- $v s$. -host disease. Blood 129:927-933.

Steenbergen L, Sellaro R, van Hemert S, Bosch JA and Colzato LS (2015) A randomized controlled trial to test the effect of multispecies probiotics on cognitive reactivity to sad mood. Brain Behav Immun 48:258-264.

Stilling RM, van de Wouw M, Clarke G, Stanton C, Dinan TG and Cryan JF (2016) The neuropharmacology of butyrate: The bread and butter of the microbiota-gut-brain axis? Neurochem Int 99:110-132.

Strati F, Cavalieri D, Albanese D, De Felice C, Donati C, Hayek J, Jousson O, Leoncini S, Renzi D, Calabrò A, et al. (2017) New evidences on the altered gut microbiota in autism spectrum disorders. Microbiome 5:24.

Suez J, Korem T, Zeevi D, Zilberman-Schapira G, Thaiss CA, Maza O, Israeli D, Zmora N, Gilad S, Weinberger A, et al. (2014) Artificial sweeteners induce glucose intolerance by altering the gut microbiota. Nature 514:181-186.

Tilg H, Grander C and Moschen AR (2016) How does the microbiome affect liver disease? Clin Liver Dis 8:123-126.

Tillisch K, Labus J, Kilpatrick L, Jiang Z, Stains J, Ebrat B, Guyonnet D, Legrain-Raspaud S, Trotin B, Naliboff B, et al. (2013) Consumption of fermented milk product with probiotic modulates brain activity. Gastroenterology 144:1394-1401.

Tremaroli V and Bäckhed F (2012) Functional interactions between the gut microbiota and host metabolism. Nature 489:242-249.

Turnbaugh PJ and Gordon JI (2009) The core gut microbiome, energy balance and obesity. J Physiol 587:4153-8.

Turnbaugh PJ, Ley RE, Hamady M, Fraser-Liggett C, Knight R and Gordon JI (2007) The human microbiome project: exploring the microbial part of ourselves in a changing world. Nature 449:804-810.

Vinolo MAR, Rodrigues HG, Nachbar RT and Curi R (2011) Regulation of inflammation by short chain fatty acids. Nutrients 3:858-876.

Wang Z, Klipfell E, Bennett BJ, Koeth R, Levison BS, DuGar B, Feldstein AE, Britt EB, Fu X, Chung YM, et al. (2011) Gut flora metabolism of phosphatidylcholine promotes cardiovascular disease. Nature 472:57-63.

Wen L, Ley RE, Volchkov PY, Stranges PB, Avanesyan L, Stonebraker AC, Hu C, Wong FS, Szot GL, Bluestone JA, et al. (2008) Innate immunity and intestinal microbiota in the development of Type 1 diabetes. Nature 455:1109-1113. 
Williams BL, Hornig M, Buie T, Bauman ML, Cho Paik M, Wick I, Bennett A, Jabado O, Hirschberg DL and Lipkin WI (2011) Impaired carbohydrate digestion and transport and mucosal dysbiosis in the intestines of children with autism and gastrointestinal disturbances. PloS One 6:e24585.

Witters P, Debbold E, Crivelly K, Vande Kerckhove K, Corthouts K, Debbold B, Andersson H, Vannieuwenborg L, Geuens S, Baumgartner M, et al. (2016) Autism in patients with propionic acidemia. Mol Genet Metab 119:317-321.

Xu K and Jiang B (2017) Analysis of mucosa-associated microbiota in colorectal cancer. Med Sci Monit Int Med J Exp Clin Res 23:4422-4430.

Yang SQ, Lin HZ, Lane MD, Clemens M and Diehl AM (1997) Obesity increases sensitivity to endotoxin liver injury: Implications for the pathogenesis of?steatohepatitis. Proc Natl Acad Sci U S A 94:2557-2562.

Yatsunenko T, Rey FE, Manary MJ, Trehan I, Dominguez-Bello MG, Contreras M, Magris M, Hidalgo G, Baldassano RN, Anokhin AP, et al. (2012) Human gut microbiome viewed across age and geography. Nature 486:222-227.

Young VB (2017) The role of the microbiome in human health and disease: An introduction for clinicians. BMJ 356:j831.

Zaki OK, El-Wakeel L, Ebeid Y, Ez Elarab HS, Moustafa A, Abdulazim N, Karara H and Elghawaby A (2016) The use of glycomacropeptide in dietary management of phenylketonuria. J Nutr Metab 2016:2453027.

\section{Internet Resources}

Ah Mew N, Simpson KL, Gropman AL, Brendan ML, Lanpher C, Chapman KA and Summar ML (2003) Urea Cycle Disorders Overview. 2003 Apr 29 [Updated 2017 Jun 22]. In: Adam MP, Ardinger HH, Pagon RA, et al., editors. GeneReviews ${ }^{\circledR}$ [Internet]. Seattle (WA): University of Washington, Seattle; 1993-2017. Available from: https://www.ncbi.nlm.nih.gov/books/NBK1217/ (November 01, 2017).

Introne WJ and Gahl WA (2003) Alkaptonuria. 2003 May 9 [Updated 2016 May 12]. In: Pagon RA, Adam MP, Ardinger HH, et al., editors. GeneReviews ${ }^{\circledR}$ [Internet]. Seattle (WA):
University of Washington, Seattle; 1993-2017. Available from: https://www.ncbi.nlm.nih.gov/books/NBK1454/ (November 01, 2017).

Metagenomics of the Human Intestinal Tract (MetaHIT), http://www.metahit.eu/ (December 09, 2017)

Online Mendelian Inheritance in Man (OMIM), http://www.ncbi.nlm.nih.gov/OMIM (July 20, 2017)

Phillips IR and Shephard EA (2007) Primary Trimethylaminuria. 2007 Oct 8 [Updated 2015 Oct 1]. In: Pagon RA, Adam MP, Ardinger $\mathrm{HH}$, et al., editors. GeneReviews ${ }^{\circledR}$ [Internet]. Seattle (WA): University of Washington, Seattle; 1993-2017. Available

from: https://www.ncbi.nlm.nih.gov/books/NBK1103/ (November 01, 2017).

Regier DS and Greene CL (2000) Phenylalanine Hydroxylase Deficiency. 2000 Jan 10 [Updated 2017 Jan 5]. In: Pagon RA, Adam MP, Ardinger HH, et al., editors. GeneReviews ${ }^{\circledR}$ [Internet]. Seattle (WA): University of Washington, Seattle; 1993-2017. Available from: https://www.ncbi.nlm.nih.gov/books/NBK1504/ (November 01, 2017).

Sniderman King L, Trahms C and Scott CR (2006) Tyrosinemia Type I. 2006 Jul 24 [Updated 2017 May 25]. In: Pagon RA, Adam MP, Ardinger HH, et al., editors. GeneReviews ${ }^{\circledR}$ [Internet]. Seattle (WA): University of Washington, Seattle; 1993-2017. Available from: https://www.ncbi.nlm.nih.gov/books/NBK1515/ (November 01, 2017).

Seckington R and Powell L (2000) HFE-Associated Hereditary Hemochromatosis. 2000 Apr 3 [Updated 2015 Sep 17]. In: Pagon RA, Adam MP, Ardinger $\mathrm{HH}$, et al., editors. GeneReviews ${ }^{\circledR}$ [Internet]. Seattle (WA): University of Washington, Seattle; 1993-2017. Available from: https://www.ncbi.nlm.nih.gov/books/NBK1440 (November 01, 2017)

Associate Editor: Maria Rita Passos-Bueno

License information: This is an open-access article distributed under the terms of the Creative Commons Attribution License (type CC-BY), which permits unrestricted use, distribution and reproduction in any medium, provided the original article is properly cited. 